What does the poet or the artist tell us? Does he not claim that what springs up within him-if it be in truth (he may add) in any valid sense his -is quite inexplicable on what he regards as psychological principles? And if psychological principles deal only with conscious integration he is right. His poetry, or his art, is not in its essential nature the outcome of perceptive or reflective integration. Its well-springs lie deeper than that in the unconscious. He rightly affirms that the real thing in all true art is beyond his conscious control, though the means by which it is expressed must be learnt and may be bettered by taking thought. This is enshrined in the proverb: Poeta nascitur non fit. And even of those who can only appreciate his work, may it not be said, with a touch of paradox, that enjoyment in art becomes reflectively conscious in criticism? This need not mean that the critic enjoys poetry any the less for the combination in higher integration of unconscious and conscious enjoyment. What it does mean is that the glad newness and glory of surprise lies in the poetry and not in the criticism. Once again it must be said that it is the fresh unexpectedness that is still the hall-mark of the unconscious.

\title{
The Age of the Earth.
}

A LTHOUGH it cannot be claimed that the A joint discussion on the "Age of the Earth," at the meeting of the British Association at Edin burgh on September I3, led to the complete reconciliation of the views of the various sections of the Association represented, there could be no doubt concerning the extraordinary interest taken in it. Members desiring admission overtaxed the capacity of one of the largest lecture theatres in Edinburgh, and shortly after the all too short discussion one might overhear in the streets of the city the remark, "They haven't settled it yet." It was quite evident that it was a good thing, if merely for the dissemination of modern views on the subject, that authoritative representatives of each science should address the same composite audience of physicists, geologists, biologists, and many who would claim none of these descriptions.

It was not surprising that the starting point of all the speakers was the inadequacy of Lord Kelvin's estimate of twenty million years for the age of the sun. Lord Rayleigh, whose lucid opening of the discussion will long be remembered, evidently believed that Kelvin had covered his estimate sufficiently with the proviso concerning sources of solar energy other than gravitation. Such sources, i.e. radio-active materials, Kelvin was unaware of, but we now know them to exist in the earth, and must presume them also to exist in the sun. Lord Rayleigh proceeded to develop his argument for arriving at the age of uranium-bearing rocks from considerations of the uranium-lead and helium which they now contain. The order and rate of radioactive disintegration through the series from uranium to lead are known with considerable precision; helium also is evolved at a definite ascertained rate. An examination of the amount of lead now present in uranium minerals enables the time when disintegration commenced to be specified, for the lead in the rocks in question proves to be not ordinary lead but wholly that isotope of atomic weight 206 which is necessarily. associated with the decay of uranium. Thus broggerite found in the pre-Cambrian rocks at Moss, Norway, contains lead of atomic weight NO. 27 I I, VOL. IO8]
206.06 ; the lead-uranium ratio is 0.113 , and this points to an age of 925 million years, upon the assumption that uranium and its products have always decayed as they do now. Estimates of age can also be made by measuring the content in rocks of that other product of disintegration-helium-although leakage of this gas makes the calculation less reliable. Allowing for this, however, the indications by helium content are generally confirmatory of those given by the leaduranium ratio. These methods can be applied to younger formations of rocks, thus obtaining the approximate age of each.

Lord Rayleigh pointed out that Prof. H. N. Russell, by applying the argument statistically to the earth's crust as a whole, arrived at the period $8 \times 10^{9}$ years as an upper limit-this being six times longer than that of any individual rock yet examined. He concluded by giving a period amounting to a moderate multiple of rooo million years as the probable duration of the earth's crust in a condition suitable for the habitation of living beings. The radio-active investigations leading to this conclusion are supported by other physical and astronomical evidence.

Prof. Sollas, who followed, made merry on behalf of the geologist, "newly enriched" from a "bankrupt" with a " mere score of millions of years" to a "bloated capitalist-with more millions in the bank than he knew how to dispose of." Within broad limits, he said, geologists were ready: to leave to the physicists the precise calculation of geological time. Some geologists, notably the brilliant and lamented Barrell, had already begun to rebuild their science on the magnified scale. For himself, he preferred first "to make sure that the new radio-active clock was not as much too fast as Lord Kelvin's was too slow." In this connection Prof. Sollas directed attention to Prof. Joly's examination of the " pleochroic haloes" occurring in uranium-bearing black mica. These haloes, which are formed by the $\alpha$-rays expelled by uranium in the various stages of its disintegration, are found generally to have ranges consistent with those obtaining in modern times. The two inner rings, however, form a notable exception, indicating ranges greater than normal 
by one-sixth, and Prof. Joly's conclusion is that in Caledonian times there existed a metope of the uranium which we now know, with possibly very different properties. If this is true, the uranium clock has not been keeping uniform time, and the true age of the earth cannot be found by presuming that it has done so.

Prof. Sollas proceeded to explain and criticise the arguments whereby geologists are seeking to modify estimates of age based upon sedimentation, sea salinity, and denudation; so as to bring them more in accordance with radio-active and other physical calculations. He evidently considered these modifications not only premature (for reasons given earlier), but to some extent unsound. Geologists, he said, are not an undivided family, and proceeded to dissent, in anticipation, from the views of Prof. J. W. Gregory, read afterwards in abstract, owing to his regrettable absence, by Prof. Jehu. The necessity for modification of the hundred million years or so, based on the original salinity argument, was stated by Prof. Gregory to be due to certain omissions and untenable assumptions. It was assumed that the sea was originally fresh, although the oldest fauna, the Cambrian, has marine characteristics, and no allowance was made for large supplies of sodium chloride raised by magmatic waters from beneath the earth's surface. Denudation also was supposed to be uniform, although it was very improbable that this had been the case. The earth is now under the influence of a time of quick movement, whereas formerly it had alternated between times of repose and activity, owing to deformations which it had undergone. (One cannot refrain from quoting Prof. Sollas's comment that "we must no longer picture a time when the earth was 'young and wantoned in her prime,' but must suppose that she has exchanged the passive indolence of youth for the fiery activity of old age.") Altogether Prof. Gregory considered that the best-known geological estimates might safely be multiplied ten- or twenty-fold, thus bringing them into line with the physical evidence.

Prof. Eddington brought forward interesting evidence based on astronomical observations. He described the observed behaviour of certain variable stars, of which $\delta$ Cephei is a typical example, in which there is strong reason for supposing that the fluctuations of intensity are due to some in- trinsic property of the star, and not to external influence. The observed change of period (itself a few days) of $\delta$ Cephei has been proved by a long series of measurements to amount to $0.08 \mathrm{sec}$. per annum, or I per cent. in 58,000 years. If the periodicity is associated with "pulsation" of the star it will be related also to the density in such a manner that the density of the star is changing at the rate of I per cent. in 29,000 years. From considerations of the luminosity of the star-a red "giant"-it would require an increase of density at the rate of $I$ per cent. in forty years to provide the necessary energy according to Lord Kelvin's gravitational contraction hypothesis. We may conclude (I) that the star certainly has sources of energy other than gravitation, and (2) that Lord Kelvin's time scale should be lengthened in the proportion $29,000: 40$, or about $700: 1$, at least during this stage of its evolution. A considerable factor of the same kind would be required for the sun also, even though its evolution has progressed much further, so that it is now a "dwarf" star.

Owing to lack of time it was not possible for Dr. H. Jeffreys to take a verbal part in the discussion, and his remarks were communicated afterwards. Dr. Jeffreys's calculations are based upon two distinct considerations: (I) the temperature distribution downwards in the earth's crust, taking into account the radio-active content; and (2) the tidal theory of the origin of the solar system. It is not possible to do them justice here, but we propose to publish them in a later issue. Both theories lead to the estimate of approximately $2 \times 10^{9}$ years since the solidification of the earth's crust, which is in remarkable agreement with the results of other physical methods.

Sir Oliver Lodge, in a few words at the end of the discussion, pleaded for justice to Kelvin, whose calculation specifically assumed that "no source of energy other than gravitation existed." But Dr. Dear, with a rare eloquence which delighted the audience, would not let the matter rest there, but asserted that Kelvin arrived at his twenty-million-year estimate by three distinct methods, and regarded it as unalterable.

In closing the discussion the president, Prof. O. W. Richardson, laid stress upon the necessity for further careful experiments for the final elucidation of the problem.

\section{The Constitution of Molecules.}

THE joint discussion on the "Constitution of Molecules"' by Sections A and B of the British Association aroused great interest, and the audience, which filled the large meeting room to its utmost capacity, included many visitors from other sections. Dr. Irving Langmuir introduced the subject with a clear and attractive presentation of the theory which is associated with his name and with that of Prof. G. N. Lewis. As originally published, this theory depended on a rather large number of arbitrary assumptions, but it has since been greatly simplified, and now involves only the three postulates described in NATURE of September I5, p. IOI. The first of these postulates, according to which the electrons arrange themselves in the atom in definite layers of $2,8,8,18,18$ and $3^{2}$, is sometimes in conflict with the third, which requires that the residual charge on each atom and group of atoms should tend to become a minimum, and by giving greater weight to 